\title{
Off-Pump Coronary Artery Bypass Grafting in Patients with St-Segment Elevation Myocardial Infarction
}

Pietro Dioguardi*

Cardiothoracic and vascular surgeon, Maria Eleonora Hospital, Italy

\begin{abstract}
Despite more than 30 years of experience with coronary artery bypass grafting (CABG), controversy still exists on the optimal timing of surgical revascularization after acute myocardial infarction (AMI). Systemic fibrinolytic treatment and primary percutaneous coronary intervention $(\mathrm{PCl})$ are both effective and represent the first-choice treatment for acute ST-segment elevation myocardial infarction (STEMI), although several randomized studies have shown that primary $\mathrm{PCl}$ is superior to thrombolytic therapy achieving early reperfusion and reducing mortality. In the last 2 decades, CABG during AMI was performed only in patients with mechanical complications or refractory cardiogenic shock (high mortality and morbidity rates). Emergency CABG in patients with STEMI is still associated with high mortality and morbidity, and the early outcome is poor compared with the outcome in patients with stable angina. Furthermore, it may be advisable to delay surgery whenever possible. However, in patients with STEMI, early surgery (within the first hours) is indicated. Current indications for emergency CABG in patients with STEMI are limited to those presenting with evolving myocardial ischemia refractory to optimal medical therapy, presence of left main stenosis or 3-vessel disease, ongoing ischemia despite successful or failed $\mathrm{PCl}$, complicated $\mathrm{PCl}$, or cardiogenic shock accompanied by complex coronary anatomy.

Operative mortality for these patients using conventional OPCABG (On-pump coronary artery bypass grafting) is from $1.6 \%$ to $32 \%$ and strongly depends on the preoperative hemodynamic condition. The use of off-pump strategies for CABG is being still debated at present. Several retrospective studies have suggested the benefits of off-pump surgery in terms of in-hospital mortality and postoperative outcomes. This chapter focuses on the impact of off-pump surgery in patients with STEMI who undergo urgent CABG.
\end{abstract}

Keywords: OFF-PUMP STEMI bypass; CABG emergency; CABG OPCABG

\section{Introduction}

Acute myocardial infarction (AMI) is the clinical syndrome leading to sudden and prolonged occlusion of a coronary branch, which leads to the ischemic necrosis of myocardial cells. Despite enormous advances in the diagnosis and treatment, coronary artery diseases (CAD) still remain a major health problem in the Western world. Moreover, more than a million patients, only in the United States, are hospitalized with suspected AMI annually in coronary care units [1]. Over the years, progressive improvement in the treatment of patients with AMI has resulted in reduced mortality. It has evolved from "clinical observation" that characterized the first half of the $20^{\text {th }}$ century, the "staged coronary unit" that began in the mid- $70^{\text {th }}$ and has played an important role in the study and treatment of arrhythmias through to the modern "era of reperfusion" introducing thrombolysis and later primary percutaneous transluminal coronary angioplasty (PTCA), stent implantation and coronary artery bypass grafting (CABG) [2].

\section{Etiopathogenesis of Myocardial Ischemia}

Almost all cases (>90\%) of AMI are caused by atherosclerosis. Histological studies of the atherosclerotic plaques often reveal, as a triggering cause of the ischemic process, the sudden change in the morphology of the plaque, such as hemorrhage, erosion, ulceration, fissuring or rupture [2-5].

The platelets are in contact with subendothelial collagen, adhering to the vessel wall and releasing powerful aggregators such as thromboxane $\mathrm{A}_{2}$, serotonin and platelet factors, which stimulate the vasospasm. At the same time released tissue thromboplastin, which activates the intrinsic pathway of coagulation, initiates clot formation. In most cases, within a few minutes, the thrombus occludes the lumen of the coronary vessel. The result of occlusion of arteries is the loss of blood supply to the myocardium downstream of the occlusion. The ischemic myocardium undergoes progressive changes in biochemical, functional and morphological properties, whose severity is related to the amount and duration of the flow interruption.

The main consequence of myocardial ischemia is anaerobic glycolysis, which produces an inadequate quantity of high-energy phosphates (creatine phosphate, adenosine triphosphate) and causes accumulation of potentially harmful catabolites such as lactic acid $[6,7]$. The function of the myocardium is affected immediately after (60 seconds) the acute event and causes a loss of contraction. The early change is reversible and does not cause cell death in a short time. The irreversible ultrastructural changes of myocytes occur after 20-40 minutes. This irreversible damage begins in the subendocardial region; if ischemia is more extensive cell necrosis spreads like a wave front to involve a larger thickness of the ischemic area [5-7].

The timing of the intervention to reverse ischemia therefore represents one of the factors favorable to the survival of patients. Within 6 hours, $70 \%$ of patients will develop a transmural AMI; this

*Corresponding author: Pietro Dioguardi, Cardiothoracic and Vascular Surgeon Maria Eleonora Hospital, GVM Care and research, V.le Regione Siciliana, 1571, Palermo 90135, Italy, Tel: +393381116757; E-mail: PT.DIOGUARDI@libero.it

Received November 25, 2013; Accepted December 16, 2013; Published December 23, 2013

Citation: Dioguardi P (2013) Off-Pump Coronary Artery Bypass Grafting in Patients with St-Segment Elevation Myocardial Infarction. J Cardiovasc Dis Diagn 1: 135. doi:10.4172/2329-9517.1000135

Copyright: (c) 2013 Dioguardi P. This is an open-access article distributed under the terms of the Creative Commons Attribution License, which permits unrestricted use, distribution, and reproduction in any medium, provided the original author and source are credited. 
percentage reaches $100 \%$ after $24 \mathrm{~h}$. Therapeutic approach for this group of patients is early reperfusion so as to ensure limitation of the infarcted area; reduce the risk of ventricular dysfunction; and increase early and long- term survival.

\section{Surgical Myocardial Revascularization for AMI}

The time between onset of symptoms and intervention is still the key of the treatment. The improvement of thrombolytic and PTCA therapies, and the reduction of mortality following AMI, has reduced the interest in CABG as a first choice for early reperfusion, relegating such a therapeutic approach only in well-defined conditions [8]. However, with the improvement of surgical techniques, anesthetic management and myocardial protection, the role for revascularization by CABG has evolved [9].

Until 30 years ago, CABG surgery in patients with a diagnosis of AMI was only indicated as a concomitant procedure while tackling acute mechanical complications of AMI. Mortality and morbidity in the short and long term for these patients were high, both for those who underwent surgery during the acute phase of the AMI as well as for those in whom surgery was delayed as a strategy to wait for evolution of the lesion.

In 1979 Steven Phillips et al. considered emergency CABG using saphenous vein bypass grafts as a possible technique of early reperfusion to effectively stop the progressive deterioration of the infarcted heart muscle. Authors found that patients operated within six hours after onset of symptoms have an increase in ejection fraction of $34 \%$, a reduction in left ventricular end-diastolic pressure by $40 \%$ and a decrease volume of the infarcted area equal to $25 \%$ [10].

In the 1980's two different groups published retrospective studies: Spokane and Des Moines. They endorsed the possible use of CABG as early reperfusion therapy for AMI. The surgery was preferable to medical therapy, as associated with lower mortality in the short and long term.

De Wood et al. reported outcomes of 701 patients who underwent CABG surgery, within 24 hours after onset of symptoms of AMI, including 440 diagnosed with STEMI and 261 with a diagnosis of non ST-segment elevation myocardial infarction (NSTEMI). Authors found a hospital mortality of $5.2 \%$ for STEMI group and 3\% for NSTEMI group [11].

The study also identified cardiogenic shock, critical preoperative state and left main stem disease as predictors of mortality [11]. Phillips et al. in 1986 published a retrospective study of 592 patients reperfused by CABG (261 patients) or PCI (331 patients), versus 146 treated medically [12].

The results obtained in terms of mortality were: $4.9 \%$ for patients undergoing reperfusion compared with $17 \%$ for patients treated with medical therapy alone.

Authors recommended the choice of thrombolysis and/or PTCA as the most appropriate method for early myocardial reperfusion for patients with single-vessel disease and CABG for patients with three vessels disease [12]. During the last 2 decade only few centers focused their research on preoperative stratification, predictors of outcomes and mortality, timing and management of surgery, in patients with AMI considered as candidates for CABG for early complete reperfusion.

Hochberg et al. performed a retrospective study of 174 patients. They reported a mortality rate for those operated within 1 week by $46 \%$ compared with $6 \%$ of those operated after 5 weeks [13]. They showed that in the first group, 50\% of patients who died were admitted in shock. Therefore they concluded that CABG was safe at any time provided that the ejection fraction (EF) was not less than 50\% [13]. In 1986, Katz et al. performed another study on 145 patients identifying EF and cardiac shock as risk factors predictive of mortality. They concluded that waiting for surgery does not reduce the risk of ventricular dysfunction and mortality rate [14]. Kouchoukos et al. performed a prospective study of 240 patients operated within 30 days after onset of symptoms [15].

In this study EF and left main coronary artery disease were predictive of mortality. They further concluded that the timing and status of emergency CABG surgery were factors that increase the operative risk [15].

In 1989, Kennedy et al. published a retrospective study of 793 patients undergoing CABG within 30 days from diagnosis of AMI, compared with a group of patients undergoing elective CABG surgery [16]. Authors found a mortality of $5.7 \%$ for the first group and $1.9 \%$ for the second, identifying EF, age and state of emergency as risk factors predictive of mortality [16]. Floten et al. analyzed 832 patients, with a diagnosis of AMI, focusing on the timing of surgery [17]. They reported a mortality of $7.6 \%$ for surgery within 24 hour from onset of symptoms and $4 \%$ for those between 1 and 7 th days and concluded that delayed CABG does not provide benefit in the long-term survival and also exposes patients to increased risk of extension of AMI and mortality [17].

Between 1990 and 1993 Sintek et al. performed a prospective study of 530 patients, reporting a mortality of $4.4 \%$ for those undergoing surgery within 24 hours, $2.1 \%$ for those operated on between the $3^{\text {rd }}$ and $7^{\text {th }}$ day and $1.4 \%$ for those operated between 1 and 4 week [18]. They identified age, site and type of AMI as risk factors predictive of mortality.

They concluded that for patients with a diagnosis of AMI in nonemergency conditions, it is possible to perform CABG surgery at any time, without an increase in mortality [18]. Recently, Lee et al. [19] published two retrospective studies of patients undergoing CABG, postAMI. They reported a mortality rate of $11.8 \%$ for patients undergoing surgery within 6 hours after onset of symptoms, 9.5\% for those operated between 6 and 24hours and $2.8 \%$ for patients who underwent surgery after 1 day. The authors concluded that CABG, performed with a diagnosis of AMI, is burdened by a high risk, with a higher mortality than the control group (treated with medical therapy).

These data confirmed that surgical intervention in patients diagnosed with AMI is legitimate. Lee et al. concluded that surgery can benefit, if delayed by at least $24 \mathrm{~h}$, especially in the presence of an AMI [19]. All data from these studies confirm the effectiveness of CABG in patients diagnosed with AMI, compared to conservative treatment, especially as regards the long-term mortality.

Many authors think that CABG for patients with early diagnosis of AMI may be performed safely especially if the patient has a condition of hemodynamic stability.

\section{Off-Pump CABG as an Early Myocardial Reperfusion Therapy}

In the past two decade, the enthusiasm for emergency CABG in evolving AMI was dampened due to the advent of thrombolytic and PTCA therapies but the failure of these measures in several cases and the appearance of post-infarction angina revived the interest in CABG both with and without $\mathrm{CPB}$ (cardiopulmonary bypass) in this cohort 
of patients. Recently, the use of off-pump beating heart surgery versus conventional on-pump surgery with cardioplegic cardiac arrest for myocardial revascularization is being intensively debated.

Theoretically, off-pump CABG seems to be an ideal procedure for patients with AMI because it preserves the coronary flow during surgery avoiding global myocardial ischemia characteristic of cardioplegic arrest period and post ischemia-reperfusion myocardial damage. Moreover, the superiority of off-pump technique versus conventional CABG in short-term cardiac outcome is well demonstrated by several randomized controlled studies [20,21]. However, it must be mentioned that most of these excluded emergency patients with AMI.

Currently, few reports are available on the postoperative outcomes of off-pump CABG in AMI patients. Mohr et al. [22] found in a group of 57 patients who underwent off-pump CABG within first week following AMI that CABG without cardiopulmonary bypass is a relatively low risk procedure. Locker et al. [23] in a series of 225 patients who underwent CABG within 7 days from onset of AMI showed that early mortality of patients operated within the first 48 hours with CPB was significantly higher compared to off-pump CABG (16.5\% vs. $4.3 \%$, $\mathrm{p}=0.044)$ but the mortality rate in patients who underwent surgery after 48 hours became similar in both groups ( $5.8 \%$ vs. $3.4 \%, \mathrm{p}=0.44$ ). They concluded that $\mathrm{CPB}$ can be used safely for most patients within the first week of AMI but for patients operated on within 48 hours from onset of symptom advocated avoiding CPB because it associated with high operative mortality.

In an another publication the same authors found that emergency off-pump CABG for AMI results in lower mortality compared with conventional CABG (5\% vs $24 \%$ ); however, the long-term results of patients operated on without $\mathrm{CPB}$ were no better than the results of those operated with $\mathrm{CPB}$, which might have been related to the incomplete revascularization or inferior patency rate of anastomoses performed on the beating heart [24]. Rastan et al. studied 638 consecutive patients with acute coronary syndrome who received emergency CABG (240 patients without CPB and 398 patients with $\mathrm{CPB}$ ) [25]. These authors concluded that beating heart surgery was associated with improved in-hospital outcomes and comparable long term results for high-risk patients presenting with acute coronary syndrome with or without cardiogenic shock. Similarly, Sergeant et al. [26] found in 269 consecutive patients with AMI that CABG can be performed with acceptable early and long-term risk in selected patients with evolving myocardial infarction, whatever the hemodynamic state. Another recent study which was performed in 2012 by Hong $S$ et al. compared the early and the long term results of off-pump coronary artery bypass grafting between patients with STEMI (group I, $n=83$ ), and NSTEMI (group II, $\mathrm{n}=237$ ). There were no significant differences in 30-day mortality and major adverse cardiac and cerebrovascular event (MACCE) between groups. Overall 8-yr survival was 93\% and $87 \%$ in groups I and II, respectively. Freedom from MACCE after $8 \mathrm{yr}$ was $92 \%$ and $93 \%$ in groups I and II, respectively. After propensity score matching analysis, there were no significant differences in preoperative parameters, postoperative in-hospital outcomes, and long-term clinical outcomes.

In our experience, overall in-hospital mortality rate was $4.7 \%$. Five patients $(7.7 \%)$ died in on-pump group and 1 patient (1.6\%) died in off-pump group ( $\mathrm{p}=0.04)$.

We found that in-hospital mortality was significantly higher in onpump versus off-pump group in patients with preoperative cardiogenic shock $(27 \%$ vs. $7.5 \%, p=0.0018)$ and in those who underwent CABG within 6 hours from onset of AMI ( $23 \%$ vs. $7.5 \%, p=0.0026)$ [27].

\section{Timing of Surgery}

The optimal timing of operation after AMI remains controversial. Locker et al. [24] demonstrated that timing in itself is not a significant predictor of early mortality in off-pump CABG but it is a significant predictor in patients operated on with $\mathrm{CPB}$.

Creswell et al. [28] reported that mortality rates of patients who underwent surgery within 6 hours after onset of AMI symptoms was $9.1 \%, 8.3 \%$ in those underwent surgery within 6 hours to 2 days, and 5.2\% within 2 to 14 days after AMI. Lee et al.[19], in a multicenter analysis showed that hospital mortality decreased considerably with increasing time interval between CABG and AMI: $11.8 \%, 9.5 \%$ and $2.8 \%$ for less than 6 hours, 6 hours to 1 day, and longer, respectively. In a recent review Weis et al. [29] reported that patients undergoing CABG within 2 days of hospitalization for AMI experienced higher mortality rates than those undergoing CABG 3 or more days after AMI, independently of clinical condition and suggested that CABG may best be deferred for 3 or more days after admission for AMI in non-urgent cases.

In our experience, incidence of early mortality in all patients operated on within 6 hours from onset of AMI and 6 hours to 2 days was $15.5 \%(4 / 26 \mathrm{pts})$ and $2 \%(2 / 101 \mathrm{pts})$, respectively ( $<<0.0001)$.

In on-pump group incidence of early death in patients operated on within 6 hours and longer than 6 hours was 23\% (3/13pts) and 3.8\% $(2 / 52 \mathrm{pts})$, respectively $(\mathrm{p}=0.006)$.

In off-pump group incidence of early death in patients operated on within 6 hours and longer than 6 hours was $7.5 \%$ (1/13 pts) and $0 \%(0 / 49 \mathrm{pts})$, respectively $(\mathrm{p}=\mathrm{ns})$ [27]. Our results were in agreement with Locker et al. [24] and suggested that timing of surgery $(<6$ hours $)$ is a significant predictor of early death in on-pump group but not in patients who underwent surgery off-pump.

The poor outcomes in the cohort of patients undergoing CABG within few hours from onset of symptoms may depend on factors such as acute left ventricular dysfunction in the early evolving phase of AMI with hemodynamic instability, appearance of post reperfusion life-treating arrhythmias, presence of collaterals to ensure coronaries run-off after acute occlusion, fibrinolytic and glycoprotein inhibitor administration that can lead to severe postoperative bleeding specifically if patients undergo on-pump CABG.

Fortunately, most AMI patients are referred to the cardiac surgeons after the first 6-12 hours but for emergency patients operated on within 6 hours from onset of symptoms, we advocate avoiding CPB because it is associated with low incidence of in-hospital mortality and improved outcomes.

\section{Impact of Preoperative Cardiogenic Shock}

Impact of preoperative cardiogenic shock on early outcome in patients who undergo CABG after AMI is still controversial. Several authors have shown that patients with AMI presenting in cardiogenic shock have poor outcome after CABG [30-33]. On the other hand, Rastan et al. [25] and Sergeant et al. [26] reported that CABG can be performed with acceptable outcome in patients with evolving AMI, whatever the preoperative hemodynamic state. In our experience, incidence of early mortality for patients presenting with cardiogenic shock was $16.5 \%$ (4/24 pts) versus $1.9 \%$ (2/103 pts) for those without shock $(\mathrm{p}<.0001)$.

In on-pump group incidence of early death in patients presenting in shock and in patients without shock was $27 \%$ (3/11 pts) and $3.7 \%$ 
$(2 / 54 \mathrm{pts})$, respectively $(\mathrm{p}=0.004)$. In off-pump group incidence of early death in patients presenting with preoperative shock and in patients without shock was $7.5 \%(1 / 13$ pts $)$ and $0 \%(0 / 49$ pts $)$, respectively $(\mathrm{p}=\mathrm{ns})$. Our data suggested that preoperative cardiogenic shock increase dramatically early mortality after CABG in patients with AMI specifically in those who underwent on-pump cardioplegic arrested heart CABG procedure [27].

\section{Risk of Conversion and Postoperative Outcomes}

In our experience, patients who underwent off-pump CABG needed less postoperative catecholamine drugs administration $(\mathrm{p}=0.02)$ and required shorter duration of inotropic support $(\mathrm{p}=0.001)$ than patients who had on-pump CABG.

Incidence of postoperative low cardiac output syndrome $(\mathrm{p}=0.001)$ and reoperation for bleeding $(\mathrm{p}=0.04)$ were significantly higher in onpump group versus off-pump group. Moreover, patients in on-pump group had longer duration of mechanical ventilation support $(\mathrm{p}=0.006)$, intensive care unit (ICU) stay $(\mathrm{p}=0.01)$ and in-hospital stay $(\mathrm{p}=0.02)$ compared to patients in off-pump group $[27,34,35]$.

Our data are in agreement with the work of Kerendi et al. [36] who reported that off-pump patients received fewer blood transfusions and had a significantly shorter postoperative ICU stay compared with onpump patients.

In our experience, the significant improvement of myocardial contractility and reduction of postoperative serum cardiac troponin I (cTnI) release in the off-pump group compared to the on-pump group may indeed be attributed to avoidance of $\mathrm{CPB}$, since complete and effective myocardial revascularization was performed in all patients in both groups (measured by intraoperative grafts flow) and all baseline characteristics of the two study groups were comparable with no statistically significant differences concerning preoperative extent of acute myocardial ischemia (measured by preoperative serum levels of cTnI and CK-MB), LVEF\%, wall motion score index, and preoperative clinical presentation being present [27].

It is known that off-pump CABG is essentially associated with an acute conversion risk, which causes death and serious complications $[37,38]$. The conversion risks are difficult to quantify and suggested predictors of conversion have included previous $\mathrm{CABG}$, congestive heart failure, AMI, low ejection fraction and a surgeon with poor experience $[37,39,40]$.

The reported conversion is from $0.4 \%$ to $2.8 \%$ [41,42]. In our study, one patient $(1.6 \%)$ in off-pump group was converted to on-pump beating heart technique during revascularization of marginal ramus for severe systemic hypotension and CABG was completed on $\mathrm{CPB}$ with good result [27].

\section{Graft Patency and Incidence of Cardiac-Related Events after Off-Pump CABG}

Completeness of revascularization and long-term graft patency are important related to off-pump CABG. Some authors found an inferior graft patency rate and recurrent symptoms for patients who underwent off-pump CABG compared with the conventional technique. Several prospective randomized trials comparing graft patency in on-pump versus off-pump surgery are available in the literature [21,43-46]. A recent meta-analysis of those trials is reported by Takagi and colleagues who found a non-statistically significant benefit of conventional CABG over off-pump CABG for overall graft patency; a pooled analysis demonstrated a statistically significant increase in overall graft occlusion with off-pump CABG relative to on-pump a sub-analysis showed a significant increase in venous graft occlusion [47].

In our experience, we found that the overall grafts patency rate were $90.7 \%$ and $91 \%$ in on-pump versus off-pump groups, respectively [34]. Furthermore, the patency rate was also similar between the two groups for arterials and saphenous vein grafts. In our series we did not observe any difference in terms of graft patency between off-pump and on-pump even of vein graft patency.

Our results are contrary to the conclusions of the two met-analyses that reported a reduction in postoperative patency of graft performed during off-pump CABG [47,48]. Recently the ROOBY trial did not report any difference in terms of adverse events within 30 days between off-pump and on-pump CABG but at one year the composite outcome (reoperation, new mechanical support, cardiac arrest, stroke, and renal failure) was higher in the off-pump group and also the graft patency was inferior [49].

On the other hand, our data gives similar results compared with the results of trials published by Kobayashi and colleagues Al-Ruzzeh and colleagues and an updated trial published by Lingaas and colleagues that showed same graft patency rates between off-pump and conventional CABG $[44,50,51]$.

Recently, Kuss et al. published a systematic review and metaanalysis of propensity score analyses showing that off-pump surgery was superior to on-pump CABG in all of the assessed short-term outcomes [52]. Our early results for the present cohort of patients were in line with the collected evidence from the randomized trials included in this recent study. Finally our results were closer to Angelini's series that showed no differences between off-pump and on-pump CABG in terms of graft occlusion and similar long term health outcome [53].

\section{Anesthetic Management and Surgical Technique}

\section{Monitoring}

The patient is positioned on a water-heating mattress in the operating room. A 5-channel ECG is recorded. The combination of leads II/V4-V5 is continuously displayed and used for ST-segment trend analysis. Capillary pulse oximetry is recorded. After local skin infiltration, one peripheral line is inserted to secure intravenous access and arterial canulation of the radial artery is performed. A pulmonary artery catheter is inserted. After induction of general anesthesia the continuous cardiac output (CO) and mixed venous oximetry is monitored. Recorded variables include cardiac index (CI), mean arterial pressure (MAP), central venous pressure, and mean pulmonary arterial pressure (mPAP), pulmonary capillary wedge pressure (PCWP), mixed venous oxygen saturation and heart rate. Hemodynamic data is obtained during conduits harvesting, after stabilizer tentacles positioning, and at 5 minutes-interval throughout the procedure. Central and peripheral temperatures are measured with nasal and rectal temperature probes. A urinary catheter is introduced to monitor urinary output.

Intraoperative transesophageal echocardiographic (TEE) control is performed in all patients to evaluate global and regional myocardial function. A 2-dimensional cardiac ultrasound from Hewlett Packard (Sonos 4500, Palo Alto, Calif) equipped with a transesophageal echocardiographic probe is used. Myocardial kinesia is evaluated in according to the guidelines of the American Society of Echocardiography. 


\section{Anesthesia}

Standard anesthesia is induced with fentanyl $(20-50 \mathrm{mg} / \mathrm{kg})$, midazolam $(0.1 \mathrm{mg} / \mathrm{kg})$, and pancuronium bromide $(0.1 \mathrm{mg} / \mathrm{kg})$, and maintained with a continuous infusion of fentanyl $(0.5-1 \mathrm{mg} / \mathrm{kg} / \mathrm{h})$ and propofol $(50-200 \mathrm{mg} / \mathrm{kg} / \mathrm{h})$. Moderate dose of opioids is used to attenuate the operative stress response.

\section{Surgical management}

Off-pump CABG is a technique that not needs a cardiopulmonary bypass. It is performed during beating heart using a commercially available suction stabilizer (Octopus, Medtronic Inc, Minneapolis, Minnesota). To reach the anterior wall for left anterior descending or diagonal arteries grafting, the surgeon places 2 to 3 moistened gauze pads behind the left ventricle to elevate and to rotate the left ventricle into the midline. In some cases, this caused compression of the right heart, which is squeezed between the thick, bulky left ventricle and the right pericardium. These results in a drop in right ventricle output, which is reflected in a decrease of mPAP, MAP, and CO. Treatment consists of filling of the heart and Trendelenburg position. In some patients with AMI who undergo early off-pump CABG, the left ventricle function is very poor and acute filling may be dangerous. In this case, the right pericardium is opened to aid heart displacement into the right pleura. A vertical incision of the pericardium at the level of the right atrium to the inferior cava vein is also applied to avoid right atrial compression.

The most challenging site to graft on the beating heart and specifically in patients with acute ischemia is the posterior wall. In order to view this invisible area from sternotomy approach, the heart must be tilted out of the pericardial cradle. Slow manipulation of the heart is necessary to avoid ventricular arrhythmias and hemodynamic deterioration. Four Lima stitches are placed deeply in the pericardium from the left pulmonary veins to the diaphragm (in midline) to push up the heart avoiding complete heart verticalization that leads to hypotension. The same procedures for the anterior wall exposure must be performed in more pronounced way. A slow apical suction cardiac positioning device (Starfish, Medtronic Inc, Minneapolis, Minnesota) can be used for revascularization of the circumflex branch. During revascularization of the lateral/posterolateral wall TEE and SvO2 monitoring are necessary because the ECG ischemia monitoring is not of value since the amplitude is decreased by the loss of contact between the heart and pericardium. Compared with LAD and right coronary artery grafting, coronary circulation is only impaired in the circumflex territory as usually the other areas have already been bypassed. Normalization of MAP with judicious use of vasoconstrictors will restore residual myocardial blood flow, as well as flow through the grafts on the anterior and inferior wall, and the situation of acute low output syndrome will disappear. It is very important to avoid overshooting with inotropic drugs. This may compromise local cardiac wall stabilization, the accuracy of the anastomosis, and cardiac performance because of increase oxygen demand.

To allow a good surgical view of the right coronary artery and its distal branches, the operating table is placed in the head-down position. A slow right ventricle anterior wall suction, close to the acute margin of the heart, is applied to facilitate vessels exposure. The suction arms are placed around the target vessel and moved ventrally in order to elevate the target area 3 to $5 \mathrm{~cm}$. This results in increase in the surgical view but it also caused some obstruction of the tricuspid orifice.

Transesophageal echocardiography as well as monitoring of right atrial pressure are helpful in identifying the limit of elevation in order to prevent tricuspid valve blockage or insufficiency. In this case, right pericardium may be opened to aid right heart displacement.

Intra-coronary shunts may be used for all anastomoses (Clearview, Medtronic Inc, Minneapolis, Minnesota). Temporary proximal occlusion of the target vessel is performed using 5-0 polypropylene sutures with Teflon pledgets. The first anastomosis is routinely performed between the left internal thoracic artery (LITA) and the LAD, but the right coronary or posterior descending artery (PDA) may be grafted first in patients with inferior AMI who undergo surgery within 12 hours from onset of symptoms. The second anastomosis is performed between the conduit and PDA and finally obtuse marginal artery is grafted.

\section{Perioperative hemodynamic management}

Grafting to the inferior and the posterolateral myocardium demands lifting of the heart partly out of the pericardium and out of the thoracic cavity. This maneuver compromises cardiac output and reduces mean arterial blood pressure. Hypotension upon dislocation of the heart is resolved by increasing preload by placing the patient in Trendelenburg position; however caution must be exercised in patients with severe acute left ventricular dysfunction due to AMI, because the acute rise in preload can lead to hemodynamic deterioration. The decrease of cardiac output and MAP are mostly caused by an outflow obstruction of the right ventricle. This is caused by a compression of the right atrium and ventricle by the displacement and torsion of the heart. This is projected in increase in central venous pressure, decrease or unchanged mPAP and decrease PCWP. This situation normally restores to acceptable hemodynamic levels without the use of vasoactive medication. Unfortunately, in patients with AMI often the hemodynamic condition deteriorates with decrease in $\mathrm{MPAP}$ and increase in PCWP necessitating vasoactive drug administration. Judicious use of alpha agonists may be necessary, despite the acute ischemic phase. Judgement must be made quite early on in such cases for conversion as emergency conversion may result in suboptimal outcome.

\section{Conclusions}

Off-pump CABG surgery appears to be the optimal treatment strategy for patients with STEMI whenever the preoperative conditions permit and CABG surgery is indicated. Although, CABG is still associated with high mortality and morbidity in patients who undergo surgery within the first 6 hours from onset of AMI symptoms and in those with cardiogenic shock, off pump surgery improves dramatically the results compared to on-pump revascularization. Maintaining native coronary blood flow during off-pump surgery avoids global myocardial ischemia, a hallmark of conventional CABG with cardioplegic arrest, and post $\mathrm{CPB}$ myocardial cell damage due to ischemia-reperfusion injury that can contribute to more postoperative left ventricular dysfunction and to poor postoperative outcome.

In our experience off-pump CABG has the same late mortality, major adverse cardiac related events, and grafts patency rate comparing to conventional CABG [34]. Furthermore, in our opinion urgent or emergent CABG for patients with STEMI can be done either way. Based on the evidence of our previous studies showing reduced early mortality and morbidity rates for patients undergoing off-pump CABG and the current literature reporting a lower incidence of postoperative outcomes such as low cardiac output, bleeding and transfusion requirements we consider that off-pump CABG may have many advantages compared with on-pump surgery for this cohort of high-risk patients [27,34,35].

As an alternative to conventional CABG for patients with AMI, 
few centers have recently adopted on-pump beating-heart CABG. On-pump beating-heart CABG is an attractive technique that keeps heart beating with the aid of CPB but without aortic cross-clamping or cardioplegic arrest. Izumi and associates demonstrated that on-pump beating-heart CABG reduces the mortality of patients with AMI and decreases the release of $\mathrm{cTnI}$ compared with conventional CABG [54].

Currently, in our opinion there are few absolute contraindications to off-pump surgery. The selection of patients should stem in large part from the operating surgeon's beating heart experience and comfort level.

Programs early in their off-pump experience should concentrate on patients with less demanding revascularization requirement. Optimal candidates for surgeons with limited experience typically include patients who are hemodynamically stable and require a limited number of bypasses located in easily accessible areas.

When surgeons start offering STEMI patients off-pump CABG, the patients' selection should include those with large target vessels free of diffuse calcified disease and hemodynamic stability despite ischemia and left ventricular dysfunction. With experience, higher risk patients with hemodynamic instability and technically more challenging procedures can be undertaken.

Difficult patients likely to benefit from off-pump surgery include those with severe left ventricular dysfunction, ischemic mitral insufficiency, or those grafted emergently after an acute myocardial infarction. Patients who are either severely hemodynamically or electrically unstable may not tolerate the manipulation required for offpump bypass grafting, and therefore represent a population generally not considered candidates for off-pump CABG. However, this subset of patients may be safely operated performing pump-supported beating heart surgery.

\section{References}

1. Fang J, Alderman MH, Keenan NL, Ayala C (2010) Acute myocardial infarction hospitalization in the United States, 1979 to 2005. Am J Med 123: 259-266.

2. Braunwald E (2003) Heart Disease. WB Saunders Company, Philadelphia USA.

3. (2000) Myocardial infarction redefined--a consensus document of The Joint European Society of Cardiology/American College of Cardiology Committee for the redefinition of myocardial infarction. Eur Heart J 21: 1502-1513.

4. Boersma E, Mercado N, Poldermans D, Gardien M, Vos J, et al. (2003) Acute myocardial infarction. Lancet 361: 847-858.

5. Fuster V, Badimon L, Badimon JJ (1992) The pathogenesis of coronary artery disease and the acute coronary syndromes. N Eng J Med 326: 310-318.

6. Rauch U, Osende JI, Fuster V, Badimon JJ, Fayad Z, et al. (2001) Thrombus formation on atherosclerotic plaques: pathogenesis and clinical consequences. Ann Intern Med 134: 224-238.

7. Ross R (1999) Atherosclerosis--an inflammatory disease. N Engl J Med 340 115-126

8. Ryan TJ, Antman EM, Brooks NH (1999) update: ACC/AHA Guidelines for the Management of Patients with Acute Myocardial Infarction: Executive Summary and Recommendations: A report of the American College of Cardiology/ American Heart Association Task Force on Practice Guidelines (Committee on Management of Acute Myocardial Infarction). Circulation 100: 1016-1030.

9. Lee DC, Ting W, Oz MC (2003) Myocardial revascularization after acute myocardial infarction. In: Cohn LH, Edmunds LH Jr (Eds). Cardiac Surgery in the Adult. McGraw-Hill, USA

10. Phillips SJ, Kongtahworn C, Zeff RH, Benson M, lannone L, et al. (1979) Emergency coronary artery revascularization: a possible therapy for acute myocardial infarction. Circulation 60: 241-246.

11. DeWood MA, Spores J, Berg R Jr, Kendall RW, Grunwald RP, et al. (1983)
Acute myocardial infarction: a decade of experience with surgical reperfusion in 701 patients. Circulation 68: $118-16$.

12. Phillips SJ, Zeff RH, Skinner JR, Toon RS, Grignon A, et al. (1986) Reperfusion protocol and results in 738 patients with evolving myocardial infarction. Ann Thorac Surg 41: 119-125.

13. Hochberg MS, Parsonnet V, Gielchinsky I, Hussain SM, Fisch DA, et al. (1984) Timing of coronary revascularization after acute myocardial infarction. Early and late results in patients revascularized within seven weeks. J Thorac Cardiovasc Surg 88: 914-921.

14. Katz NM, Kubanick TE, Ahmed SW, Green CE, Pearle DL, et al. (1986) Determinants of cardiac failure after coronary bypass surgery within 30 days of acute myocardial infarction. Ann Thorac Surg 42: 658-663.

15. Kouchoukos NT, Murphy S, Philpott P (1988) Coronary artery bypass graft surgery after acute myocardial infarction. Circulation 79: 68-72.

16. Kennedy JW, Ivey TD, Misbach G, Allen MD, Maynard C, et al. (1989) Coronary artery bypass graft surgery early after acute myocardial infarction. Circulation 79: 173-78.

17. Floten HS, Ahmad A, Swanson JS, Wood JA, Chapman RD, et al. (1989) Long term survival after postinfarction bypass operation: early versus late operation. Ann Thorac Surg 48: 757-762.

18. Sintek CF, Pfeffer TA, Khonsari S (1994) Surgical revascularization after acute myocardial infarction. Does timing make a difference? J Thorac Cardiovasc Surg 107: 1317-1321.

19. Lee DC, Oz MC, Weinberg AD, Lin SX, Ting W (2001) Optimal timing of revascularization: transmural versus nontransmural acute myocardial infarction. Ann Thorac Surg 71: 1197-1202.

20. van Dijk D, Nierich AP, Jansen EW, Nathoe HM, Suyker WJ, et al. (2001) Early outcome after off-pump versus on-pump coronary bypass surgery: results from a randomized study. Circulation 104: 1761-1766.

21. Khan NE, De Souza A, Mister R, Flather M, Clague J, et al. (2004)A randomized comparison of off-pump and on-pump multivessel coronary-artery bypass surgery. N Engl J Med 350: 21-28

22. Mohr R, Moshkovitch Y, Shapira I, Amir G, Hod H, et al. (1999) Coronary artery bypass without cardiopulmonary bypass for patients with acute myocardial infarction. J Thorac Cardiovasc Surg 118: 50-56.

23. Locker C, Mohr R, Paz Y, Kramer A, Lev-Ran O, et al. (2003) Myocardial revascularization for acute myocardial infarction: benefits and drawbacks of avoiding cardiopulmonary bypass. Ann Thorac Surg 76: 771-776.

24. Locker C, Shapira I, Paz Y, Kramer A, Gurevitch J, et al. (2000) Emergency myocardial revascularization for acute myocardial infarction: survival benefits of avoiding cardiopulmonary bypass. Eur J Cardiothorac Surg 17: 234-238.

25. Rastan AJ, Eckenstein JI, Hentschel B, Funkat AK, Gummert JF, et al. (2006) Emergency coronary artery bypass graft surgery for acute coronary syndrome. Beating heart versus conventional cardioplegic cardiac arrest strategies. Circulation 114: 477-485

26. Sergeant $P$, Blackstone E, Meyns B (1997) Early and late outcome after CABG in patients with evolving myocardial infarction. Eur J Cardiothorac Surg 11: 848-856.

27. Fattouch K, Guccione F, Dioguardi P, Sampognaro R, Corrado E, et al. (2009) Off-pump versus on-pump myocardial revascularization in patients with ST-segment elevation myocardial infarction: a randomized trial. J Thorac Cardiovasc Surg 137: 650-656.

28. Creswell LL, Moulton MJ, Cox JL, Rosenbloom M (1995) Revascularization after acute myocardial infarction. Ann Thorac Surg 60: 19-26.

29. Weiss ES, Chang DD, Joyce DL, Nwakanma LU, Yuh DD (2008) Optimal timing of coronary artery bypass after acute myocardial infarction: a review of California discharge data. J Thorac Cardiovasc Surg 135: 503-511, 511.

30. Kaul TK, Fields BL, Riggins SL (1995) Coronary artery bypass grafting within 30 days of an acute myocardial infarction. Ann. Thorac. Cardiovascular Surg 59:1169-1176.

31. Yamagishi I, Sakurada T, Abe T (1998) Emergency coronary artery bypass grafting after acute myocardial infarction. What influences early postoperative mortality? Ann Thorac Cardiovasc Surg 4: 28-33.

32. Wasvary H, Shannon F, Bassett J, O'Neill W (1997) Timing of coronary artery bypass grafting after acute myocardial infarction. Am Surg 63: 710-715. 
Citation: Dioguardi P (2013) Off-Pump Coronary Artery Bypass Grafting in Patients with St-Segment Elevation Myocardial Infarction. J Cardiovasc Dis Diagn 2: 135. doi:10.4172/2329-9517.1000135

33. Quigley RL, Milano CA, Smith LR, White WD, Rankin JS, et al. (1993) Prognosis and management of anterolateral myocardial infarction in patients with severe left main disease and cardiogenic shock. The left main shock syndrome. Circulation 88: II65-70.

34. Fattouch K, Runza G, Moscarelli M, Trumello C, Incalcatera E, et al. (2011) Graft patency and late outcomes for patients with ST-segment elevation myocardial infarction who underwent coronary surgery. Perfusion 26: 401-408.

35. Fattouch K, Bianco G, Speziale G, Sampognaro R, Lavalle C, et al. (2007) Beneficial effects of $\mathrm{C} 1$ esterase inhibitor in ST-elevation myocardial infarction in patients who underwent surgical reperfusion: a randomised double-blind study. Eur J Cardiothorac Surg 32: 326-332.

36. Kerendi F, Puskas JD, Craver JM, Cooper WA, Jones EL, et al. (2005) Emergency coronary artery bypass grafting can be performed safely without cardiopulmonary bypass in selected patients. Ann Thorac Surg 79: 801-806.

37. Edgerton JR, Dewey TM, Magee MJ, Herbert MA, Prince SL, et al. (2003) Conversion in off-pump coronary artery bypass grafting: an analysis of predictors and outcomes. Ann Thorac Surg 76: 1138-1142.

38. Légaré JF, Buth KJ, Hirsch GM (2005) Conversion to on pump from OPCAB is associated with increased mortality: results from a randomized controlled trial. Eur J Cardiothorac Surg 27: 296-301.

39. Reeves BC, Ascione R, Caputo M, Angelini GD (2006) Morbidity and mortality following acute conversion from off-pump to on-pump coronary surgery. Eur $\mathrm{J}$ Cardiothorac Surg 29: 941-947.

40. Vassiliades TA Jr, Nielsen JL, Lonquist JL (2002) Hemodynamic collapse during off-pump coronary artery bypass grafting. Ann Thorac Surg 73: 1874-1879.

41. Hart JC, Spooner TH, Pym J, Flavin TF, Edgerton JR, et al. (2000) A review of 1,582 consecutive Octopus off-pump coronary bypass patients. Ann Thorac Surg 70: 1017-1020.

42. Anyanwu AC, Al-Ruzzeh S, George SJ, Patel R, Yacoub MH, et al. (2002) Conversion to off-pump coronary bypass without increased morbidity or change in practice. Ann Thorac Surg 73: 798-802.

43. Puskas JD, Williams WH, Mahoney EM, Huber PR, Block PC, et al. (2004) Off-pump vs conventional coronary artery bypass grafting: early and 1-year graft patency, cost, and quality-of-life outcomes: a randomized trial. JAMA 291 1841-1849.

44. Al-Ruzzeh S, George S, Bustami M, Wray J, Ilsley C, et al. (2006) Effect of off- pump coronary artery bypass surgery on clinical, angiographic, neurocognitive, and quality of life outcomes: randomised controlled trial. BMJ 332: 1365

45. Widimsky P, Straka Z, Stros P, Jirasek K, Dvorak J, et al. (2004) One-year coronary bypass graft patency: a randomized comparison between off-pump and on-pump surgery angiographic results of the PRAGUE-4 trial. Circulation 110: $3418-3423$

46. Nathoe HM, van Dijk D, Jansen EW, Suyker WJ, Diephuis JC, et al. (2003) A comparison of on-pump and off-pump coronary bypass surgery in low-risk patients. N Engl J Med 348: 394-402.

47. Takagi H, Tanabashi T, Kawai N, Kato T, Umemoto T (2007) Off-pump coronary artery bypass sacrifices graft patency: meta-analysis of randomized trials. $J$ Thorac Cardiovasc Surg 133: e2-3.

48. Parolari A, Alamanni F, Polvani G, Agrifoglio M, Chen YB, et al. (2005) Metaanalysis of randomized trials comparing off-pump with on-pump coronary artery bypass graft patency. Ann Thorac Surg 80: 2121-2125.

49. Shroyer AL, Grover FL, Hattler B, Collins JF, McDonald GO, et al. (2009) Onpump versus off-pump coronary-artery bypass surgery. $\mathrm{N}$ Engl J Med 361 : 1827-1837.

50. Kobayashi J, Tashiro T, Ochi M, Yaku H, Watanabe G, et al. (2005) Japanese Off-pump Coronary Revascularization Investigation (JOCRI) Study Group. Early outcome of a randomized comparison of off-pump and on-pump multiple arterial coronary revascularization. Circulation. 112: 338-343.

51. Lingaas PS, Hol PK, Lundblad R, Rein KA, Mathisen L, et al. (2006) Clinica and radiologic outcome of off-pump coronary surgery at 12 months follow-up: a prospective randomized trial. Ann Thorac Surg 81: 2089-2095.

52. Kuss O, von Salviati B, Börgermann J (2010) Off-pump versus on-pump coronary artery bypass grafting: a systematic review and meta-analysis of propensity score analyses. J Thorac Cardiovasc Surg 140: 829-835, 835.

53. Angelini GD, Culliford L, Smith DK, Hamilton MC, Murphy GJ, et al. (2009) Effects of on- and off-pump coronary artery surgery on graft patency, survival and health-related quality of life: long-term follow-up of 2 randomized controlled trials. J Thorac Cardiovasc Surg 137: 295-303.

54. Izumi Y, Magishi K, Ishikawa N, Kimura F (2006) On-pump beating-heart coronary artery bypass grafting for acute myocardial infarction. Ann Thorac Surg 81: 573-576. 